\title{
Given the Demographics of Emotional Divorce of Spouses - How to Minimize It, Using Structural Equation Modeling: A Case Study in Egypt
}

\author{
Yasser Abdelazim Abdelmawgoud Samak (Corresponding author) \\ Faculty of Arts, Department of Geography and GIS, Assiut University, Old University \\ Building, M.B,71515, Assiut, Egypt \\ E-mail: geopsychologie@gmail.com
}

\author{
Mogeda El Sayed El-Keshky
}

King Abdulaziz University, Department of Psychology, Faculty of Arts and Humanities, P.O. Box 42803, Jeddah 21551, Saudi Arabia

\section{Shatha Jamil Khusaifan}

King Abdulaziz University, Department of Psychology, Faculty of Arts and Humanities, P.O. Box 42803, Jeddah 21551, Saudi Arabia

Received: October 23, 2016 Accepted: November 22, 2016 Published: November 23, 2016

doi:10.5296/ijsw.v3i2.10200 URL: http://dx.doi.org/10.5296/ijsw.v3i2.10200

\begin{abstract}
This study identifies eight factors: age, gender, education, occupation, place of residence, duration of marriage, number of previous marriages and number of children within the marriage, which can affect the occurrence of emotional divorce. These eight factors are explored through nine dimensions: emotional, intellectual, social-recreational, psychological, temporal, sexual, spiritual, physical and economic. Exploratory and Confirmatory Factor Analysis and path diagrams are used to extract emotional divorce from the eight factors. Structural Equation Modeling (SEM) is run to verify the above factor structure and evaluate the influence of each variable on emotional divorce. The corresponding beta coefficients in
\end{abstract}


the regression equations reveal that education is the most dominant predictor of emotional divorce, with a 5\% level of significance. It is equally predominant through seven of the nine dimensions (all excluding temporal). It is concluded that demographic factors such as age, gender and education levels play an important role in people's day-to-day lives, particularly within marriages.

Keywords: Emotional divorce, Marital satisfaction, Divorce in Egypt, Structural equation modeling, Factor analysis

\section{Introduction}

Emotional divorce can occur gradually between spouses, often without the conscious awareness of the couple. Emotional divorce describes a situation where, with the passage of time, both partners can experience a sense of emotional detachment from one another (Beach et al., 1990; Christensen \& Heavey, 1999). Although there is no substantial evidence to support any link between emotional divorce and marital quality, it has been observed that emotional divorce is a common factor among many couples prior to their legal divorce or separation (Berg \& Kelly, 1979).

\section{Dimensions of a Marital Relationship}

\subsection{Emotional Dimension}

Emotional stress can be a major determinant of marital quality, and in this context, Lavee et al. (1996) have concluded that the stress of performing the role of parents is proportionally greater for the husband and wife the more children there are within a marriage. The link between marital quality and the parental-child relationship has also been confirmed by Erel and Burman (1995). Different emotional response patterns which have an impact on a couple's perception of marital quality, such as hostility, optimism and neuroticism (Newton \& Kiecol-Glacier, 1995; Lin \& Raghubir, 2005; Whisman et al., 2004; Coyne et al., 2002), have been studied by Tucker and Friedman (1996) in the context of their association with poor physical health.

\subsection{Social-Recreational Dimension}

The socioeconomic status of spouses can also influence divorce rates, and this has been studied by Jalovaara (2002), who observed that a wife's increasing experience in a field of work can induce husbands to think of divorce. This has been corroborated by Huber and Spitze (1980). The impact of unemployment of the husband or wife on divorce has been studied by Amato and Beattie (2011) from two perspectives. The correlation between unemployment and marital instability that can lead to divorce has also been confirmed by Jones (2008).

\subsection{Intellectual Dimension}

Intellectual intimacy can be maintained when husband and wife can comfortably share their ideas and experiences with each other. Schaefer and Olson (1981) have studied how individuals perceive intellectual intimacy in their marital life. Greef and Malherbe (2011) 
have concluded that intellectual intimacy is positively related to marital satisfaction for both men and women. Talmadge and Dabbs (1990) found that the level of intellectual intimacy is less between couples who have been married for a longer period than for couples who have been married for shorter periods.

\subsection{Sexual Dimension}

Physical intimacy is another strong factor which affects the harmony of marital relations. The quality of the sexual relationship between marital partners is greatly influenced by the anxiety felt by each party stemming from a worry that their partner may reject or abandon them. Based on this theory, Butzer and Campbell (2008) have observed that individuals who take an avoidance approach towards their sexual relationship provide a low level of sexual satisfaction to their partners (Shaver \& Hazan 1988). Isaac and Shah (2004) found that couples who exhibit androgynous traits have a high level of marital adjustment capability.

\subsection{Physical and Temporal Dimensions}

Ammar (2006) has studied the impact of physical violence on married couples. The author has observed that physical violence can reduce the reproductive capacity of women, and this is more common among women who have been subjected to unintended pregnancies. Domestic violence also has an adverse effect on children, as confirmed by Holt et al. (2008) and Levendosky and Graham-Bermann (2001). Katz and Gottman (1993) observed that marital conflicts between mutually hostile partners that culminate in marriage dissolution can have an adverse impact on the behavioral patterns of their children, particularly with regard to how they interact with other people. Thus, the temporal factor comes into play. Such effects are still evident three years after their parents' divorce. Lopez (1993) argues that such behavior (domestic violence) is construed as 'lack of sensitivity', and often this can induce feelings of neglect in the other partner. One important determinant of marital quality is the behavioral pattern of one partner as perceived by the other partner (Williams, 1979). One partner may behave in a manner that is unexpected and unwelcomed by the other partner, for instance, forgetting birthdays and anniversaries.

\subsection{Spiritual Dimension}

Mahoney et al. (2009) observed that the majority of couples, both husbands and wives, considered their marriage and pregnancies as spiritual and a reflection of God. These perceptions were further linked to three spiritual aspects described as 'spiritual behavioral investment, spiritual emotions, and positive spiritual coping' (Mahoney et al., 2009, p. 1). The fact that women tend to feel a spiritual awareness during pregnancy has been corroborated by a study conducted by Carver and Ward (2013) on Australian couples.

\subsection{Economic Dimension}

Gibson-Davis (2009) inferred that cohabiting couples may decide to marry and subsequently have children based on their level of income. It was observed that if the income of cohabiting couples is reduced for any reason, then they are $37 \%$ less likely to marry. The influence of income is more dominant among low income couples than for their high income counterparts, since the former engage in more effective money management than the latter (Godwin \& Koonce, 1992). 


\subsection{Psychological Dimension}

The ninth dimension, the psychological impact of an absentee father on his children, has been studied by McLanahan et al. (2013), who observed that the pattern of impact is further influenced by the age of the children during the period their father was absent. Barber and Eccles (1992) observed that there is an adverse impact on children, not just as a direct result of the divorce itself, but also as a result of the consequences of divorce, such as the limited resources of some single mothers. In the context of marriage's effect on individual psychology, Gove et al. (1983) observed that - more than marriage itself - it is the quality of married life that has the greater positive impact on the psychological health of individuals (Gottman, 1998).

The purpose of the current study is to examine the predictive factors of emotional divorce, evaluate the impact of demographic factors (such as age, gender, education, occupation, place of residence, duration of marriage, number of previous marriages and the number of children within a marriage) on emotional divorce and assess the relative impact on emotional divorce of emotional, intellectual, social-recreational, psychological, temporal, sexual, spiritual, physical and economic dimensions. Given that emotional divorce is a much broader concept than intimacy, and encompasses many dimensions of marital quality, it has been accepted as a valid construct of marital quality in this paper.

\section{Materials and Methods}

\subsection{Research Approach}

The research follows a quantitative method and the results are analyzed using both exploratory and confirmatory analysis. A pilot study was undertaken in 12 randomly selected Egyptian governorates whereby questionnaires were sent to participants via Google forms and data was also collected during direct interviews to ensure the inclusion of participants who were not familiar with computers and the internet. A total of 355 questionnaires were completed (Note 1).

\subsection{Analytical Approach: Reliability, Validity and Factor Extraction}

The questionnaire in the present study contained 159 questions with a Likert scale of degree 5. The reliability analysis yielded a Cronbach's alpha score of 0.971 , i.e., the questionnaire items have $97.1 \%$ internal consistency. The Cronbach's alpha score is well above the widely accepted margin of 0.7 (Nunnaly, 1978), hence the questionnaire is reliable.

Using the KMO measure of sampling adequacy, it was calculated that the questionnaire items combined with the sample size gave an $86.2 \%$ (0.862) adequacy score for factor analysis, which is satisfactory. Bartlett's Test of Sphericity yields a statistically significant $(p<0.001)$ $\chi^{2}$ value. Therefore, Exploratory Factor Analysis (EFA) can successfully extract latent factors. The eight extracted factors (in this case: age, gender, education, occupation, place of residence, duration of marriage, number of previous marriages and number of children within the marriage) account for $54.707 \%$ of the total variance, which meets the minimum requirement of 50\%. 'Maximum Likelihood' has been used as the method of extraction in this analysis, as it is considered to be the best modern method for EFA. The factors have been 


\section{Macrothink}

International Journal of Social Work

ISSN $2332-7278$

2016, Vol. 3, No. 2

extracted as per Eigenvalues (Russell, 2007).

Confirmatory Factor Analysis (CFA) is derived using a Rotated Variable Matrix. The path diagram in Figure 1 illustrates this association with eight variables generated from EFA loading variables. All the path coefficients are well above the 0.5 threshold value (Segars \& Grover, 1993). Significant path coefficients indicate stability of the model (Anderson and Gerbing, 1988). For a fit model it is expected that the p-value of chi-square statistics should be more than 0.05 . In this model, the chi-square $\left(\chi^{2}\right)$ value is 2245.63 , its p-value is less than 0.05 and its degrees of freedom (df) is 1246. The value of chi-square/df (CMIN/df) is less than 10 (1.802). The indices which compare the model with null or independent models show acceptance and rejection. The Comparative Fit Index (CFI) illustrates the ratio of 'difference between $\chi^{2}-\mathrm{df}$ of null and hypothesized model' to $\chi^{2}-\mathrm{df}$ of the null model. To be acceptable, the model should have a CFI measure of 0.9 . This model satisfactorily meets the requirement, with a CFI of 0.9. The Incremental Fit Index (IFI) is affected by sample size. For calculation of IFI, first the difference between the chi-square of the null model - in which variables are uncorrelated - and the chi-square of the hypothesized model is calculated. Next, the difference between the chi-square of the hypothesized model and the df for the hypothesized model is calculated. The ratio of these values represents the IFI. An acceptable IFI score is equal to or above 0.9. This model meets the index requirement. The Tucker Lewis Index (TLI) is a similar model-fitness index and also requires 0.9 or above. This model is approaching optimum fitness when calculated using 


\section{Macrothink}

International Journal of Social Work

ISSN 2332-7278

2016, Vol. 3, No. 2

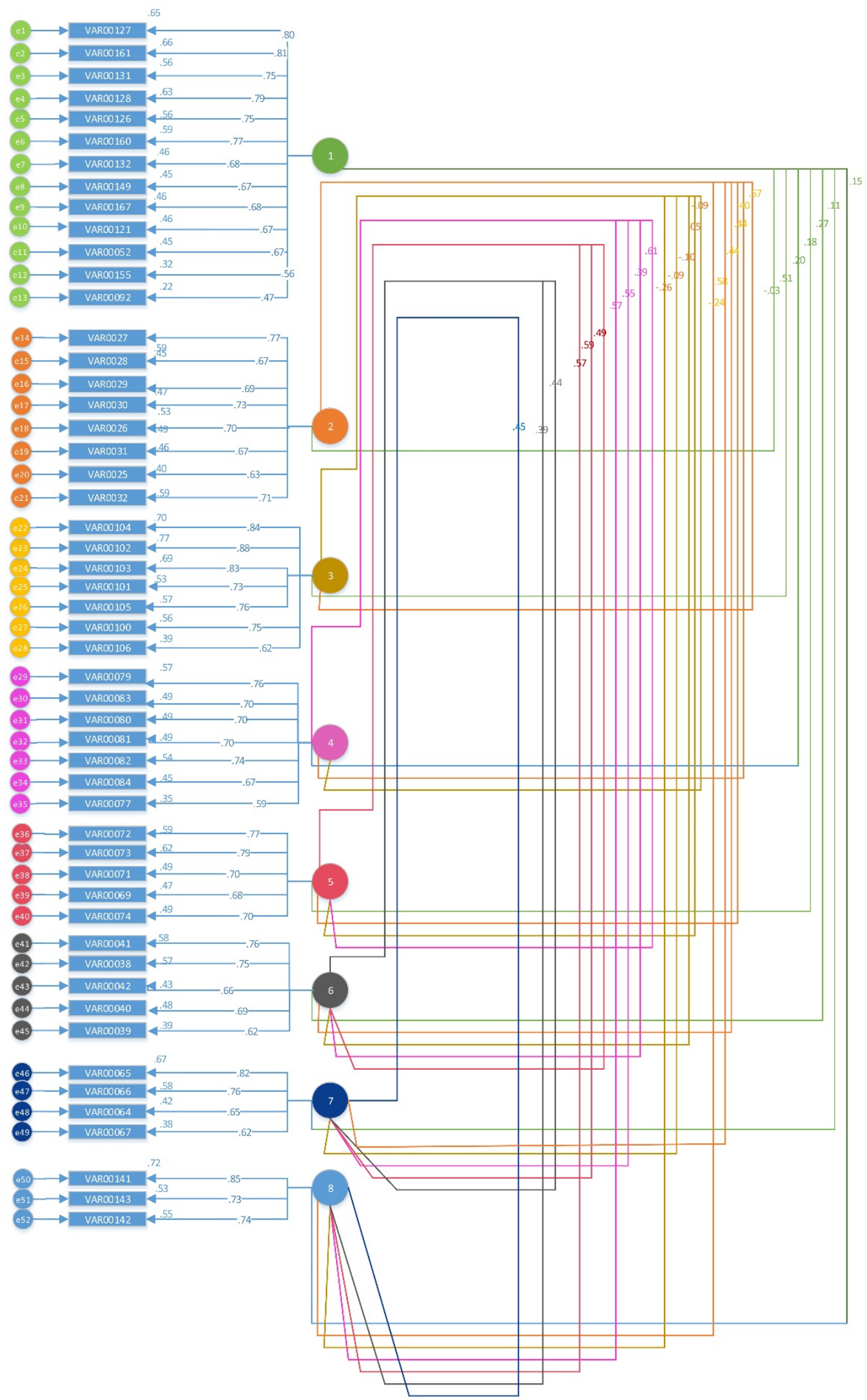

Figure 1. Confirmatory factor analysis (CFA) with the questionnaire items 
TLI. The Normed Fit Index (NFI) is calculated as the ratio of 'difference of $\chi^{2}$ between null and hypothesized model' to the null model. This model does not meet the requirement of 0.9 for NFI. The Relative Fit Index (RFI) compares the chi-square for the hypothesized model to baseline model. This model does not meet the index requirement of 0.9. The Root Mean Square Error of Approximation (RMSEA) analyzes the issues between hypothesized and null models without considering sample size. For a good fit, the model RMSEA must be equal to or below 0.08. This model meets that requirement with a value of .058 . The Root Mean Residual (RMR) value is less than 0.1 , and, since this indicator demonstrates lack of fit, a lower value corresponds to a better fit (Kline, 2005).

\subsection{Predictive Factors}

First it is important to test if there is a predictor, i.e., an independent variable that statistically significantly influences the dependent variable: 'emotional divorce'. This can be undertaken in two steps - first, the dependent variable, emotional divorce, is extracted and evaluated in relation to its nine dimensions using EFA, and second, once the dependent variable emotional divorce has been extracted, a Structural Equation Modeling (SEM) analysis is conducted to illustrate the relationship between the independent variables and the dependent variable (See Figure 2).

EFA has been conducted to extract emotional divorce from its dimensions (emotional, intellectual, social-recreational, psychological, temporal, sexual, spiritual, physical, economic). The factor extraction is very satisfactory, as the KMO score of 0.937 is much greater than 0.6, with a df of 36 and a significant Bartlett's Test of Sphericity. The total variance explained is $81.407 \%$, and only one factor has been extracted automatically by Eigenvalue.

\section{Results}

\subsection{Dimensions}

Emotional divorce has the utmost impact on the emotional dimension. The respective beta coefficient shows that for a unit increase in emotional divorce, the emotional aspects will change by 0.99 units. Conversely, the economic dimension is least influenced by emotional divorce occurrences, and this is reflected in the coefficient 0.712 (lowest). This implies that a spouse's life process, work or income is not generally affected by a damaged relationship between the marital couple. Alternatively, it could be theorized that spouses focus more on income generation when their emotional involvement with one other is lessened. Less intuitively, it appears that the sexual, spiritual and physical dimensions are also not overly affected by a lack of emotional involvement. This may be explained by the fact that even if the couples engage in physical or sexual intimacy, they may still lack a high level of compassion or love for each other. Therefore physical intimacy might be perceived as a routine aspect of marital life rather than as a consequence of love. Hence, emotional divorce also does not have any strong impact on sexual relations.

\subsection{Evaluating Predictors}

SEM illustrates the relationship between the predictors and emotional divorce. The model 
chi-square is significant (193.823; df: 28). However, this measure is not important, as the sample size is small. Only education has a statistically significant relationship ( $p$-value of 0.031 ), with emotional divorce at a $5 \%$ level of significance. The relationship is negative. Therefore, an increase in educational level decreases the tendency to emotional divorce. None of the indices that compare the hypothesized and null models are satisfactory. However, the GFI (Goodness of Fit) is satisfactory (as it is close to 0.9) and chi-square/df (CMIN/df) is less than 10 (6.922), hence the model is a satisfactory fit. Therefore, education is a significant and negative determinant of emotional divorce. This finding has also been proved by Karney and Bradbury (1999).

Multi-group data looking at demographical factors may be analyzed using SEM. For the male group, the model chi-square is significant (107.08; df: 27). However, this measure is not important, as the sample size is small. For both male and female groups, the emotional dimension is affected in the same way by emotional divorce (the coefficient in the factor matrix is 0.99). For other dimensions, the effect is greater in the female group. The approximation error is above the acceptable level of 0.10 .

The indices comparing the hypothesized and null models are all satisfactory for the male and female groups. For the male group, the value of CMIN/df is less than 10 (3.966) and therefore satisfactory. As the CFI is very satisfactory, it nullifies the requirement of the RMSEA to be less than 0.08 (RMSEA is 0.166 ). For the female group, the model chi-square is significant (110.51; df: 27). However, this measure is not important, as the sample size is small. The ratio CMIN/df is less than 10 (4.093) and therefore satisfactory. Since the CFI is also very satisfactory for the female group, it nullifies the requirement of RMSEA to be less than 0.08 (RMSEA is 0.152 ).

The model fit is explored for four category levels of education: moderate, above average, university and post-graduate. Considering the magnitude of the effects, there are certain dimensions in which the effects (following the beta coefficient values on single head arrows) are different between the categories, and others in which there is relatively no difference. The sexual and economic dimensions are less affected by emotional divorce within the moderate and above average groups (the beta coefficients for the sexual dimension are 0.88 and 0.85 respectively) compared to the university and post-graduate groups (beta coefficients for the sexual dimension are 0.92 and 0.90 respectively). The physical dimension is less affected by emotional divorce for the moderate education group (beta coefficient of 0.75 ) and most affected within the post-graduate category (beta coefficient of 0.91 ). With regard to the level of fit, there is little difference between the four categories. Level of fit indices are high and above the thresholds that demonstrate a good fit. Only in two instances is the NFI slightly below the threshold for a good fit (0.90), the above average (NFI is 0.883 ) and post-graduate groups (NFI is 0.888). In both segments the approximation error is beyond the acceptable level of 0.10 . The models in Figure 2 show that priority (beta coefficients) differs between education levels. For the group with post-graduate level education, the model chi-square is significant (57.931; df: 27). However, this measure is not important, as the sample size is small. The ratio of CMIN/df is less than 10 (2.146) and therefore satisfactory. The indices that compare the hypothesized and null models are all satisfactory. As the CFI is very satisfactory, it nullifies the requirement of RMSEA to be less than 0.08 (RMSEA is 0.186). 


\section{Macrothink}

International Journal of Social Work

ISSN $2332-7278$

2016, Vol. 3, No. 2

For the sample group with university level education, the model chi-square is significant (96.53; df: 27) at 5\% level of significance. However, this measure is not important, as the sample size is small. The CMIN/df ratio is less than 10 (3.575) and is therefore satisfactory. The indices that compare the hypothesized and null models are also all satisfactory. GFI is less than the minimum required value of 0.9 and hence not satisfactory, however, the RMR is low and acceptable. As the CFI is very satisfactory, it nullifies the requirement of the RMSEA to be less than 0.08 (RMSEA is 0.161). For the sample group with an above average education level, the model chi-square is significant (46.581; df: 27). However, this measure is not important, as the sample size is small. The ratio of CMIN/df is less than 10 (1.725) and therefore satisfactory. The indices that compare the hypothesized and null models are all satisfactory. GFI is less than 0.9 and not satisfactory, however, the RMR is low and satisfactory. As the CFI is very satisfactory it nullifies the requirement of the RMSEA to be less than 0.08 (RMSEA is 0.164 ). For those with a moderate level of education, the model chi-square is significant (89.372; df: 27). However, this measure is not important, as the sample size is small. 


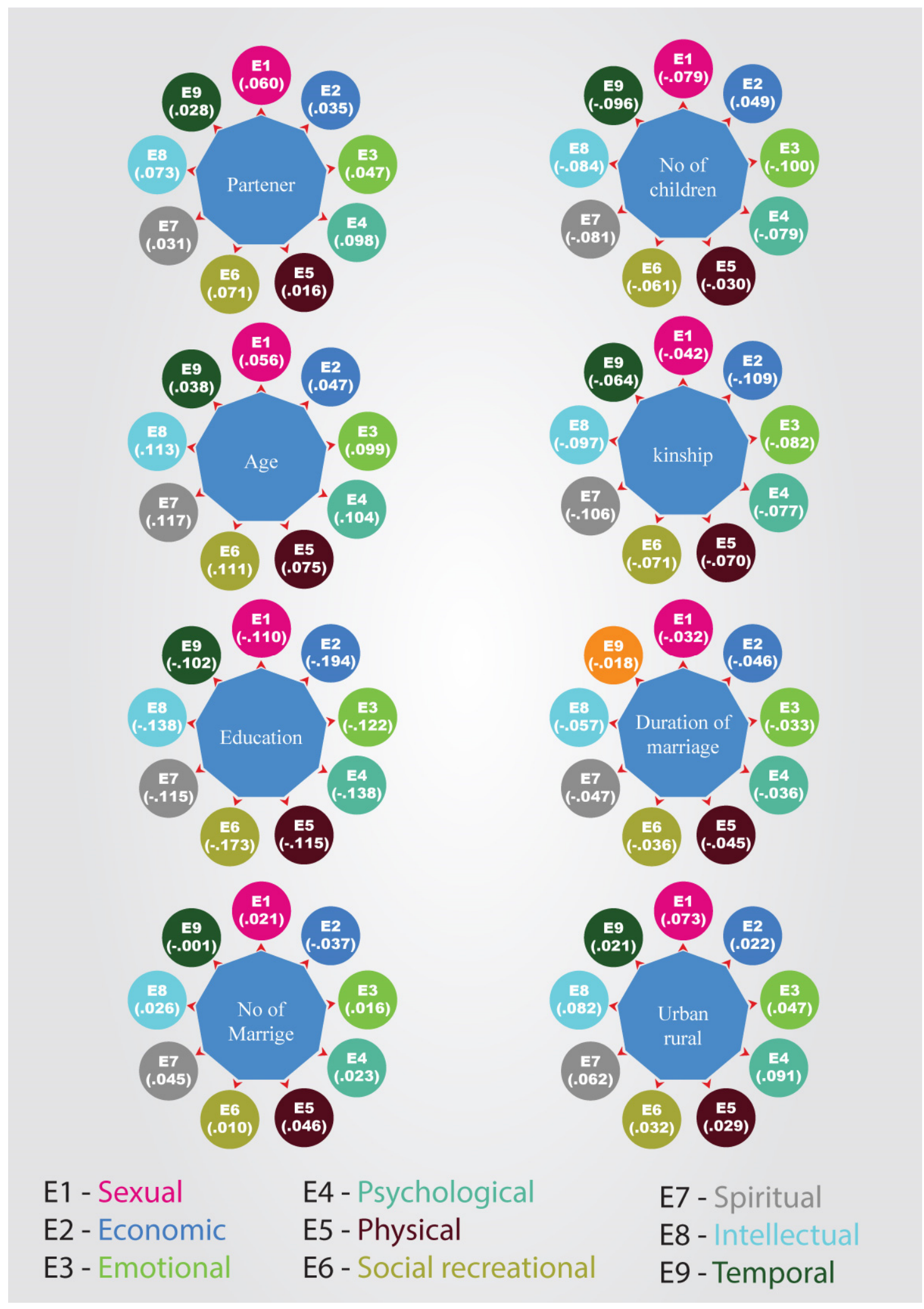

Figure 2. The relation between all the independent variables and dimensions of emotional divorce

Figure 2 shows that emotional dimension is the most influential dimension of emotional 


\section{Macrothink}

International Journal of Social Work

ISSN 2332-7278

2016, Vol. 3, No. 2

divorce. Emotional dimension has the highest coefficient (.99) and Education is influencing it significantly. Only education has a significant relation.

The ratio CMIN/df is less than 10 (3.310) and is therefore satisfactory. The indices that compare the hypothesized and null models are all satisfactory. As the CFI is very satisfactory, it nullifies the requirement of the RMSEA to be less than 0.08 (RMSEA is 0.176). GFI is lower than 0.9 and is also satisfactory (See Table 1.).

Table 1. Goodness of fit and Baseline comparisons for male and female groups

\begin{tabular}{|c|c|c|c|c|c|c|c|c|c|}
\hline & Male & & & & & & & & \\
\hline \multirow{2}{*}{ Model } & \multirow{2}{*}{ Chi-square $\left(\chi^{2}\right)$} & NFI & RFI & IFI & TLI & \multirow{2}{*}{ CFI } & \multirow{2}{*}{ RMR } & \multirow{2}{*}{ GFI } & \multirow[t]{2}{*}{ RMSEA } \\
\hline & & Delta1 & rhol & Delta2 & rho2 & & & & \\
\hline $\begin{array}{l}\text { Default } \\
\text { model }\end{array}$ & 107.079 & 0.922 & 0.896 & 0.941 & 0.92 & 0.94 & 0.03 & 0.824 & .166 \\
\hline $\begin{array}{l}\text { Saturated } \\
\text { model }\end{array}$ & 0 & 1 & & 1 & & 1 & 0 & 1 & \\
\hline \multirow{2}{*}{$\begin{array}{l}\text { Independence } \\
\text { model }\end{array}$} & 1377.829 & 0 & 0 & 0 & 0 & 0 & 0.585 & 0.172 & .587 \\
\hline & \multicolumn{8}{|l|}{ Female } & \\
\hline $\begin{array}{l}\text { Default } \\
\text { model }\end{array}$ & 110.507 & 0.948 & 0.931 & 0.96 & 0.947 & 0.96 & 0.023 & 0.847 & .152 \\
\hline $\begin{array}{l}\text { Saturated } \\
\text { model }\end{array}$ & 0 & 1 & & 1 & & 1 & 0 & 1 & \\
\hline $\begin{array}{l}\text { Independence } \\
\text { model }\end{array}$ & 2129.898 & 0 & 0 & 0 & 0 & 0 & 0.842 & 0.149 & .661 \\
\hline
\end{tabular}

Table 1: Fit indices included: goodness of fit index (GFI), root mean square error of approximation (RMSEA), the maximum likelihood estimation Chi square $\left(\chi^{2}\right)$; the incremental fit index (IFI), the Tucker Lewis index (TLI) and the comparative fit index (CFI) $* p \backslash .000$.

A unit change in emotional divorce is affected by an increase in the social and recreational dimension of employed couples by 0.96 , while the dimension which least influences emotional divorce is the economic dimension (by 0.73 ) for employed couples. The sexual dimension also has little effect on emotional divorce within the professional classes, compared to other influences. For the clerical class, the model chi-square is significant (67.379; df: 27). However, this measure is not important, as the sample size is small. The ratio $\mathrm{CMIN} / \mathrm{df}$ is less than $10(2.496)$ and is therefore satisfactory. The indices that compare the hypothesized and null models are all satisfactory. GFI is not satisfactory. As the CFI is very satisfactory, it nullifies the requirement of the RMSEA to be less than 0.08 (RMSEA is 


\section{NI Macrothink}

International Journal of Social Work

ISSN 2332-7278

2016, Vol. 3, No. 2

$0.151)$.

For the employed group, the model chi-square is significant (45.227; df: 27). However, this measure is not important, as the sample size is small. The ratio of CMIN/df is less than 10 (1.675) and is therefore satisfactory. The indices that compare the hypothesized and null models are all satisfactory. As the CFI is very satisfactory, it nullifies the requirement of RMSEA to be less than 0.08 (RMSEA is 0.116). For those with a specialist education, the model chi-square is significant (89.339; df: 27). However, this measure is not important, as the sample size is small. The CMIN/df ratio is less than 10 (3.309) and is therefore satisfactory. The indices that compare the hypothesized and null models are all satisfactory. As the CFI is very satisfactory, it nullifies the requirement of the RMSEA to be less than 0.08 (RMSEA is 0.203). However, GFI is not satisfactory. For regular professional workers, the model chi-square is significant (51.510; df: 27). However, this measure is not important, as the sample size is small. The ratio CMIN/df is less than 10 (1.908) and is therefore satisfactory. The CFI and the IFI are satisfactory. As the CFI is very satisfactory, it nullifies the requirement of the RMSEA to be less than 0.08 (RMSEA is 0.255). GFI is also satisfactory and hence the fit is good.

For staff working in the service sector, the model chi-square is significant (41.361; df: 27). However, this measure is not important, as the sample size is small. The ratio CMIN/df is less than 10 (1.532) and is therefore satisfactory. The indices that compare the hypothesized and null models are all satisfactory but GFI is not. As CFI is very satisfactory, it nullifies the requirement of the RMSEA to be less than 0.08 (RMSEA is 0.182). For technicians, the model chi-square is significant (66.955; df: 27). However, this measure is not important, as the sample size is small. The ratio CMIN/df is less than $10(2.480)$ and is therefore satisfactory. The indices that compare the hypothesized and null models are all satisfactory. As the CFI is very satisfactory (See Table 2), it nullifies the requirement of the RMSEA to be less than 0.08 (RMSEA is 0.218 ). However, GFI is not satisfactory.

Therefore, it is demonstrated that the influence on the dimensions of emotional divorce varies with gender, education and occupation. The fact that husband and wife react differently to each dimension of emotional divorce has also been noted by Strong et al. (2010). Based on an IBM work and life survey, the results of Hill et al. (2001) confirmed the fact that occupation can influence emotional divorce dimensions. 
Table 2. Baseline Comparisons and Goodness of Fit for association of indicators with dimensions of Emotional Divorce

\begin{tabular}{llllllllll}
\hline Model & Chi-square $\left(\chi^{2}\right)$ & $\begin{array}{l}\text { NFI } \\
\text { Delta1 }\end{array}$ & $\begin{array}{l}\text { RFI } \\
\text { rho1 }\end{array}$ & $\begin{array}{l}\text { IFI } \\
\text { Delta2 }\end{array}$ & $\begin{array}{l}\text { TLI } \\
\text { rho2 }\end{array}$ & CFI & RMR GFI & RMSEA \\
$\begin{array}{l}\text { Default model } \\
\begin{array}{l}\text { Saturated } \\
\text { model }\end{array}\end{array}$ & .000 & .020 & -1.082 & .020 & -1.123 & .001 & 1.061 & .256 & .483 \\
$\begin{array}{l}\text { Independence } \\
\text { model }\end{array}$ & 3751.486 & .000 & & 1.000 & & 1.000 & .000 & 1.000 & \\
\hline
\end{tabular}

The previous CFA clearly shows that the emotional dimension is the most influential variable. The SEM model below illustrates which independent variables are significantly associated with this dimension. It shows the calculated beta coefficients. As per the model, education remains the independent variable with the most significant relationship to the emotional dimension. The model chi-square is significant (193.823; df: 28). However, this measure is not important, as the sample size is small. The ratio CMIN/df is less than 10 (6.922) and is therefore satisfactory. Neither of the indices that compare the hypothesized and null models is satisfactory. The RMSEA is not satisfactory (RMSEA is 0.156 ). GFI is satisfactory and hence the model is a good fit.

The SEM in Figure 1 illustrates the relationships between all the independent variables and the dimensions of emotional divorce. The model chi-square is significant (3676.165; df: 64). However, this measure is not important, as the sample size is small. The ratio CMIN/df is less than 10 (57.440) and is therefore not satisfactory. Neither the RMSEA at 0.483 nor GFI is satisfactory. The regression weights (See appendix 1) and coefficients in Table 1 show that education has a statistically significant relationship (with at least $90 \%$ confidence) with all the dimensions, excluding 'temporal'. Age is also an important independent variable, as it has a statistically significant relationship (with at least $90 \%$ confidence) with the social recreational, psychological, spiritual and intellectual dimensions.

Therefore, one may infer that both education and age have a significant relationship with nearly all the dimensions of emotional divorce. Age was considered as a factor because an older person may possess the greater maturity needed to handle situations and conflict in the marriage. However, at $95 \%$, education is the only variable which significantly affects most dimensions of emotional divorce. Education may, in fact, have a significant role to play in regulating emotions (Aldao, 2013). Previous research by Li and Fung (2011) found that age is significant for the husband's marital quality, whereas no similar link was found for wives. The age group between 20 to 55 years is mostly affected by the occurrence of emotional divorce. However, the dimensions most affected are social, recreational, psychological, spiritual and intellectual, rather than emotional. This shows that emotions are not dependent on age. 


\section{Conclusions}

The CFA reveals that the emotional dimension is the most important of all the variables and the economic dimension is the least important. The importance of the emotional dimension has been confirmed by Whisman et al. (2004). Godwin and Koonce (1992) also found that the economic dimension is least important, especially between high income married couples. The model chi-square (186.091; df: 27) of the CFA is significant. However, this measure is not important because the sample size is small. The ratio CMIN/df is less than 10 (6.892) and is therefore satisfactory. The indices that compare the hypothesized and null models are all satisfactory. GFI is satisfactory, whereas the RMSEA is not (RMSEA is 0.156).

Emotional divorce is significantly related to the emotional dimension. A recent study undertaken in Iran suggested that emotional divorce could be the consequence of rational calculation (Barzoki et al., 2015). Such instances of divorce are often based on factors that stress the different perceived relative status of men and women, for example, a culture of patriarchy and female passivity, a sense of inequality and unequal exchange, all of which can be logically explained. However, such factors are very dependent on the culture within different societies. This research was conducted in Egypt where the relative perceived inequality between male and female spouses is lower. This factor could explain the difference in results between this study and the Iranian research.

From the CFA, it can be seen that there is no significant relationship between emotional divorce and whether a couple describe their place of residence as 'urban' or 'rural', because the p-value (0.453) is greater than the 0.05 threshold. Kinship and the number of children within a marriage are similarly not statistically significantly related to emotional divorce, since the p-values are greater than 0.05 ( 0.111 and 0.190 respectively). Likewise, Allendorf and Ghimire (2013) failed to establish any correlation between marital quality and a couple's number of children. There is also no relationship between emotional divorce and a couple's age or the duration of their marriage, since the p-values are greater than $0.05(0.113$ and 0.595 respectively). There is no relationship between a couple's place of residence and the psychological dimension of emotional divorce ( $p$-value of0.142). Place of residence also does not influence the sexual dimension of emotional divorce ( $p$-value of 0.249). Level of education has a statistically significant relationship (with minimum $90 \%$ confidence) with the intellectual, emotional and sexual dimensions of emotional divorce ( $p$-values of 0.113 and 0.375 respectively). Age has a significant relationship to the intellectual dimension (with minimum $90 \%$ confidence), demonstrated by a p-value of 0.068 . Duration of marriage has no relationship with the intellectual, emotional and sexual dimensions (all have corresponding p-values greater than 0.10). However, previous studies, including Charles and Carstensen (2010) and Allendorf and Ghimire (2013) contradict this finding. Those studies found that length of marriage was a major determinant of marital quality. SEM shows that an urban or rural place of residence bears no relation to any dimensions of emotional divorce.

\section{Steps Spouses can Take to Develop Emotional Satisfaction}

1) Keep in mind that each of you has different emotional needs. 


\section{MInstitute Macrothink $_{\text {Int }}$}

International Journal of Social Work

ISSN 2332-7278

2) Remember that as your confidence in marital satisfaction increases, you'll both be more likely to take more care of each other.

3) Listen to each other so you both feel accepted and understood.

4) Respect each other and recognize that the needs of both of you will change over time.

5) Admire each other's distinctive characteristics and dedicate yourself to acting for your spouse's well-being.

6) Be confident in the developing capacity of each of you to experience a sense of security and peace of mind.

7) Ascertain what each couple needs to do to achieve their goal, and reassure them that the behaviors suggested will lead to increased marital stability.

8) Help each couple acquire the knowledge and unique personal skills they need so they can enjoy the benefits of their emotional intelligence and thus reduce the risk of divorce in general and emotional divorce, in particular.

9) Households with greater income and opportunities for higher education are more likely to avail themselves of any provided marital advice than those with low income and education.

\section{Some Suggestions for Helping Couples Succeed in Developing Their Marital Satisfaction}

1) Teach basic skills to couples for problem solving, and for facing frustration and boredom at the social care home.

2) Help couples' develop the ability to deal with their spouse's character weaknesses so they can adapt how they operate together and thus reduce the incidence of divorce.

3) Provide governmental material aid and incentives to parents caring for their children full-time, in order to make life easier for the poorest families and develop their social environment.

The limitation of the research described herein lies in the fact that only 12 governorates of Egypt have been considered, and the period of study was also limited (June to September 2013). Despite these drawbacks, some pointers for policymakers may be inferred. The findings suggest that governing bodies should focus on raising the average educational level of the population such that cases of emotional divorce, which often lead to separation, can be avoided. In addition, couples should use their wisdom and be given access to counselors and lawyers who can educate them regarding the importance of understanding within the marriage and who can suggest practical means of rejuvenating the relationship in order to minimize the instances of emotional divorce.

\section{Possible Avenues for Future Research}

1) Study of the roles of positive and negative emotions/feelings in marital satisfaction.

2) Study of the relationships between the social skills involved in mutual, effective responses by couples and individual assertiveness.

3) Examination of the need for emotional support given the psychological pressures within the couple relationship that derive from their individual functioning and personality traits. 


\section{References}

Ajiboye, L. (2014). Inferiority Complex, A Seemingly Harmless Personality Blemish of Grave Societal Consequences, Trafford Publishing.

Aldao, A. (2013). The Future of Emotion Regulation Research. Perspectives on Psychological Science, 8(2), 155-172. https://doi.org/10.1177/1745691612459518

Allendorf, K., \& Ghimire, D. J. (2013). Determinants of marital quality in an arranged marriage society. Social Science Research, 42(1), 59-70. https://doi.org/10.1016/j.ssresearch.2012.09.002

Amato, P. R., \& Beattie, B. (2011). Does the unemployment rate affect the divorce rate? Social Science Research, 40(3), 705-715. https://doi.org/10.1016/j.ssresearch.2010.12.012

Ammar, N. H. (2006). Beyond the shadows: Domestic spousal violence in a "democratizing" Egypt. Trauma, Violence, and Abuse, 7(4), 244-259. https://doi.org/10.1177/1524838006292520

Anderson, J. C., \& Gerbing, D. W. (1988). Structural equation modeling in practice: A review and recommended two-Step approach. Psychological Bulletin, 103(3) 411-423. https://doi.org/10.1037/0033-2909.103.3.411

Barber, B. L., \& Eccles, J. S. (1992). Long-term influence of divorce and single parenting on adolescent family- and work-related values, behaviors, and aspirations. Psychological Bulletin, 111(1), 108-126. https://doi.org/10.1037/0033-2909.111.1.108

Barzoki et al. (2015). Rational-emotional 'divorce' in Iran. Applied Research in Quality of Life, 10(1), 107-122. https://doi.org/10.1007/s11482-014-9303-9

Beach, S., et al. (1990). Depression in marriage: A model for etiology and treatment. Guilford Press.

Carstensen, L. L., et al. (1996). Affect in intimate relationships. In C. Magai, \& S. H. McFadden (Eds.), Handbook of emotion, adult development and aging (pp. 222-248). Academic Press. https://doi.org/10.1016/b978-012464995-8/50014-5

Carver, N., \& Ward, B. (2013). Spirituality in pregnancy: A diversity of experiences and needs. British Journal of Midwifery, 15(5), 294-296. https://doi.org/10.12968/bjom.2007.15.5.23410

Charle, S., \& Carstensen, L. L. (2010). Social and emotional aging. Annual Review of Psychology, 61(1), 383-409. https://doi.org/10.1146/annurev.psych.093008.100448

Christensen, A., \& Heavey, C. L. (1999). Interventions for couples. Annual Review of Psychology, 50(1), 165-190. https://doi.org/10.1146/annurev.psych.50.1.165

Coyne J. C., Thompson, R., \& Palmer, S. C. (2002). Marital quality, coping with conflict, marital complaints, and affection in couples with a depressed wife. Journal of Family Psychology, 16(1), 26-37. https://doi.org/10.1037/0893-3200.16.1.26 
Erel, O., \& Burman, B. (1995). Interrelatedness of marital relations and parent-child relations: A meta-analytic review. Psychological Bulletin, 118(1), 108-132. https://doi.org/10.1037/0033-2909.118.1.108

Fincham, F. D., \& Beach, S. R. (1999). Conflict in marriage: Implications for working with $\begin{array}{lllll}\text { couples. Annual Review of Psychology, } & 50(1), & \text { 47-77. }\end{array}$ https://doi.org/10.1146/annurev.psych.50.1.47

Gibson-Davis, C. M. (2009). Money, marriage, and children: Testing the financial expectations and family formation theory. Journal of Marriage and Family, 71(1), 149-160. https://doi.org/10.1111/j.1741-3737.2008.00586.x

Godwin, D. D., \& Koonce, J. C. (1992). Cash flow management of low-income newlyweds. Financial Counseling and Planning, 3, 17-42.

Gottman, J. M. (1998). Psychology and the study of marital processes. Annual Review of Psychology, 49(1), 169-197. https://doi.org/10.1146/annurev.psych.49.1.169

Greef, A. P., \& Malherbe, H. L. (2001). Intimacy and marital satisfaction in spouses. Journal of Sex \& Marital Therapy, 27(3), 247-257. https://doi.org/10.1080/009262301750257100

Hadi, A. M. (2012). Emotional divorce and its relationship to self effectively among families. Dar Annahda Alarabiya (pp. 44-47) (In Arabic ).

Hill, E. J., et al. (2001). Finding an extra day a week: The positive influence of perceived job flexibility on work and family life balance. Family Relations, 50(1), 49-58. https://doi.org/10.1111/j.1741-3729.2001.00049.x

Holt, S., et al. (2008). The impact of exposure to domestic violence on children and young people. Child Abuse \& Neglect, 32(8), 797-810. https://doi.org/10.1016/j.chiabu.2008.02.004

Huber, J., \& Spitze, G. (1980). Considering divorce: An expansion of Becker's Theory of Marital Instability. American Journal of Sociology, 86(1), 75-89. https://doi.org/10.1086/227203

Isaac, R., \& Shah, A. (2004). Sex roles and marital adjustment in Indian couples. International Journal of Social Psychiatry, 50(2), 129-141. https://doi.org/10.1177/0020764004040960

Jalovaara, M. (2002). Socioeconomic differentials in divorce risk by duration of marriage. Demographic Research, 7(16), 537-564. https://doi.org/10.4054/DemRes.2002.7.16

Jiang et al. (2013). Locke-Wallace Short Marital-Adjustment Test: Psychometric evaluation in caregivers for persons with primary malignant brain tumor. Journal of Nursing Measurement, 21(3), 502-515. https://doi.org/10.1891/1061-3749.21.3.502

Jones, L. (2008). The relationship between unemployment and divorce. Journal of Divorce, 12(1), 99-112. https://doi.org/10.1300/J279v12n01_06

Kaiser, H. F., \& Rice J. (1974). Little Jiffy, Mark IV. Educational and Psychological 
Measurement, 34(1), 111-117. https://doi.org/10.1177/001316447403400115

Karney, B. R., \& Bradbury, T. N. (1995). The longitudinal course of marital quality and stability: A review of theory, method, and research. Psychological Bulletin, 118(1), 3-34. https://doi.org/10.1037/0033-2909.118.1.3

Katz, L. F., \& Gottman, J. M. (1993). Patterns of marital conflict predict children's internalizing and externalizing behaviors. Developmental Psychology, 29(6), 940-950. https://doi.org/10.1037/0012-1649.29.6.940

Kiecolt-Glaser, J. K., \& Newton, T. L. (2001). Marriage and health: His and hers. Psychological Bulletin, 127(4), 472-503. https://doi.org/10.1037/0033-2909.127.4.472

Kline, T. (2005). Psychological Testing. SAGE.

Koolaee, A., et al. (2010). The comparison of relationship beliefs and couples burnout in women who apply for divorce and women who want to continue their marital life. Iranian Journal of Psychiatry, 5(1), 35-39.

LaPierre, T. A., \& Hill, S. A. (2013). Examining status discrepant marriages and marital quality at the intersection of gender, race and class. In M. H. Kohlman, et al. (Eds.), Notions of family: Intersectional perspectives (pp.113-136). Emerald Group Publishing. https://doi.org/10.1108/S1529-2126(2013)0000017009

Lavee, Y., et al. (1996). The effect of parenting stress on marital quality. Journal of Family Issues, 17(1), 114-135. https://doi.org/10.1177/019251396017001007

Levendosky, A. A., \& Graham-Bermann, S. A. (2001). Parenting in battered women: The effects of domestic violence on women and their children. Journal of Family Violence, 16(2), 171-192. https://doi.org/10.1023/A:1011111003373

Li, T., \& Fung, H. H. (2011). Partner discrepancies and age differences in marital quality: Distinguishing the ideal, expected, and perceived partner. The Journals of Gerontology, 67(4), 417-422. https://doi.org/10.1093/geronb/gbr119

Lin, Y-C., \& Raghubir, P. (2005). Gender differences in unrealistic optimism about marriage and divorce: Are men more optimistic and women more realistic? Personality and Social Psychology Bulletin, 31(2), 198-207. https://doi.org/10.1177/0146167204271325

Lopez, F. G. (1993). Cognitive processes in close relationships. Journal of Counseling and Development, 71, 310. https://doi.org/10.1002/j.1556-6676.1993.tb02218.x

Mahoney, A., et al. (2009). In R. L. Piedmont, \& A. Village (Eds.), Research in the social scientific study of religion (pp. 1-46). BRILL.

McLanahan, S., et al. (2013). The casual effects of father absence. Annual Review of Sociology, 39, 399-427. https://doi.org/10.1146/annurev-soc-071312-145704

Newton, T. L., \& Kiecol-Glacier, J. K. (1995). Hostility and erosion of marital quality during early marriage. Journal of Behavioral Medicine, 18(6), 601-619. 
https://doi.org/10.1007/BF01857898

Nunnaly, J. (1978). Psychometric theory. New York: McGraw-Hill.

Russell, D. W. (2007). In search of underlying dimensions: The use (and abuse) of factor analysis in Personality and Social Psychology Bulletin. Personality and Social Psychology Bulletin, 28, 1629-46. https://doi.org/10.1177/014616702237645

Schaefer, M. T., \& Olson, D. H. (1981). Accessing intimacy: The pair inventory. Journal of Marital and Family Therapy, $47-60$. https://doi.org/10.1111/j.1752-0606.1981.tb01351.x

Segars, A. H., \& Grover, V. (1993). Re-examining perceived ease of use and usefulness: A confirmatory factor analysis. MIS Quarterly, 17(4), 517-525. https://doi.org/10.2307/249590

Shaver, P. R., \& Hazan, C. (1988). A biased overview of the study of love. Journal of Social and Personal Relationships, 5(4), 473-501. https://doi.org/10.1177/0265407588054005

Strong, B., et al. (2010). The marriage and family experience: Intimate relationships in a changing society. Cengage Learning.

Tabachnick, B. G., \& Fidell, L. S. (2001). Using multivariate statistics (4th ed.) Boston: Allyn and Bacon.

Talmadge, L. D., \& Dabbs, J. M. (1990). Intimacy, conversational patterns and concomitant cognitive/emotional processes in couples. Journal of Social and Clinical Psychology, 9(4), 373-488. https://doi.org/10.1521/jscp.1990.9.4.473

Tucker, J. S., \& Friedman, H. S. (1996). Emotion, personality and health. In C. Magai, \& S. H. McFadden (Eds.), Handbook of emotion, adult development, and aging (pp. 305-326). Academic Press. https://doi.org/10.1016/b978-012464995-8/50018-2

Whisman, M. A., et al. (2004). Psychopathology and marital satisfaction: The importance of evaluating both partners. Journal of Consulting and Clinical Psychology, 72(5), 830-838. https://doi.org/10.1037/0022-006X.72.5.830

Williams, A. M. (1979). The quantity and quality of marital interaction related to marital satisfaction: A behavioral analysis. Journal of Applied Behavior Analysis, 12(4), 665-678. https://doi.org/10.1901/jaba.1979.12-665

Note 1. The scale used to study the emotional divorce was prepared by the principal author Dr: Yasser Abdelazim Samak, and is in the process of being printing for publication. 


\section{Appendices}

Appendix 1. Regression weights for each indicator with dimensions of emotional divorce

\begin{tabular}{|c|c|c|c|c|}
\hline \multicolumn{3}{|c|}{ Parameters Interaction } & \multirow{2}{*}{$\begin{array}{l}\text { Estimate } \\
.120\end{array}$} & \multirow{2}{*}{$\begin{array}{l}\mathrm{P} \\
.346\end{array}$} \\
\hline Sexual & $<---$ & Partner & & \\
\hline Economic & $<---$ & Partner & .071 & .573 \\
\hline Emotional & $<---$ & Partner & .096 & .451 \\
\hline Psychological & $<---$ & Partner & .198 & .116 \\
\hline Physical & $<---$ & Partner & .032 & .802 \\
\hline Social_recreational & $<---$ & Partner & .144 & .254 \\
\hline Spiritual & $<---$ & Partner & .064 & .616 \\
\hline Intellectual & $<---$ & Partner & .149 & .238 \\
\hline Temporal & $<---$ & Partner & .055 & .664 \\
\hline Sexual & $<---$ & Age & .007 & .375 \\
\hline Economic & $<---$ & Age & .006 & .452 \\
\hline Emotional & $<---$ & Age & .012 & .113 \\
\hline Psychological & $<---$ & Age & .013 & .094 \\
\hline Physical & $<---$ & Age & .009 & .238 \\
\hline Social_recreational & $<---$ & Age & .014 & .074 \\
\hline Spiritual & $<---$ & Age & .015 & .061 \\
\hline Intellectual & $<---$ & Age & .014 & .068 \\
\hline Temporal & $<---$ & Age & .005 & .550 \\
\hline Sexual & $<---$ & Education & -.094 & .082 \\
\hline Economic & $<---$ & Education & -.166 & .002 \\
\hline Emotional & $<---$ & Education & -.105 & .051 \\
\hline Psychological & $<---$ & Education & -.119 & .027 \\
\hline Physical & $<---$ & Education & -.099 & .068 \\
\hline Social_recreational & $<---$ & Education & -.149 & .005 \\
\hline Spiritual & $<---$ & Education & -.099 & .066 \\
\hline Intellectual & $<---$ & Education & -.119 & .027 \\
\hline Temporal & $<---$ & Education & -.087 & .109 \\
\hline
\end{tabular}




\begin{tabular}{|c|c|c|c|c|}
\hline \multicolumn{3}{|c|}{ Parameters Interaction } & \multirow{2}{*}{$\begin{array}{l}\text { Estimate } \\
.036\end{array}$} & \multirow{2}{*}{$\begin{array}{l}\mathrm{P} \\
.736\end{array}$} \\
\hline Sexual & $<---$ & No_of_Marriage & & \\
\hline Economic & $<---$ & No_of_Marriage & -.063 & .554 \\
\hline Emotional & $<---$ & No_of_Marriage & .027 & .804 \\
\hline Psychological & $<---$ & No_of_Marriage & .040 & .708 \\
\hline Physical & $<---$ & No_of_Marriage & .079 & .464 \\
\hline Social_recreational & $<---$ & No_of_Marriage & .018 & .867 \\
\hline Spiritual & $<---$ & No_of_Marriage & .077 & .476 \\
\hline Intellectual & $<---$ & No_of_Marriage & .045 & .674 \\
\hline Temporal & $<---$ & No_of_Marriage & -.002 & .985 \\
\hline Sexual & $<---$ & No_of_children & -.053 & .210 \\
\hline Economic & $<---$ & No_of_children & .033 & .433 \\
\hline Emotional & $<---$ & No_of_children & -.067 & .111 \\
\hline Psychological & $<---$ & No_of_children & -.053 & .204 \\
\hline Physical & $<---$ & No_of_children & -.020 & .639 \\
\hline Social_recreational & $<---$ & No_of_children & -.041 & .324 \\
\hline Spiritual & $<---$ & No_of_children & -.055 & .195 \\
\hline Intellectual & $<---$ & No_of_children & -.056 & .178 \\
\hline Temporal & $<---$ & No_of_children & -.064 & .129 \\
\hline Sexual & $<---$ & Kinship & -.088 & .502 \\
\hline Economic & $<---$ & Kinship & -.226 & .081 \\
\hline Emotional & $<---$ & Kinship & -.171 & .190 \\
\hline Psychological & $<---$ & Kinship & -.160 & .216 \\
\hline Physical & $<---$ & Kinship & -.144 & .271 \\
\hline Social_recreational & $<---$ & Kinship & -.147 & .257 \\
\hline Spiritual & $<---$ & Kinship & -.221 & .090 \\
\hline Intellectual & $<---$ & Kinship & -.202 & .118 \\
\hline Temporal & $<---$ & Kinship & -.132 & .312 \\
\hline Sexual & $<---$ & Duration_of_marriage & -.005 & .611 \\
\hline Economic & $<---$ & Duration_of_marriage & -.007 & .465 \\
\hline
\end{tabular}




\begin{tabular}{|c|c|c|c|c|}
\hline \multicolumn{3}{|c|}{ Parameters Interaction } & \multirow{2}{*}{$\begin{array}{l}\text { Estimate } \\
-.005\end{array}$} & \multirow{2}{*}{$\begin{array}{c}\mathrm{P} \\
.595\end{array}$} \\
\hline Emotional & $<---$ & Duration_of_marriage & & \\
\hline Psychological & $<---$ & Duration_of_marriage & -.005 & .563 \\
\hline Physical & $<---$ & Duration_of_marriage & -.007 & .481 \\
\hline Social_recreational & $<---$ & Duration_of_marriage & -.005 & .568 \\
\hline Spiritual & $<---$ & Duration_of_marriage & -.007 & .451 \\
\hline Intellectual & $<---$ & Duration_of_marriage & -.009 & .360 \\
\hline Temporal & $<---$ & Duration_of_marriage & -.003 & .777 \\
\hline Sexual & $<---$ & Urban_rural & .148 & .249 \\
\hline Economic & $<---$ & Urban_rural & .046 & .719 \\
\hline Emotional & $<---$ & Urban_rural & .096 & .453 \\
\hline Psychological & $<---$ & Urban_rural & .187 & .142 \\
\hline Physical & $<---$ & Urban_rural & .059 & .648 \\
\hline Social_recreational & $<---$ & Urban_rural & .065 & .610 \\
\hline Spiritual & $<---$ & Urban_rural & .128 & .318 \\
\hline Intellectual & $<---$ & Urban_rural & .169 & .185 \\
\hline Temporal & $<---$ & Urban_rural & .042 & .744 \\
\hline
\end{tabular}

Appendix 1 shows that education has statistically significant (with at least $90 \%$ confidence) relation with all the dimensions except temporal. Age is also an important independent variable as it has statistically significant (with at least $90 \%$ confidence) relation with social recreational, psychological, spiritual and intellectual dimensions.

\section{Copyright Disclaimer}

Copyright reserved by the author(s).

This article is an open-access article distributed under the terms and conditions of the Creative Commons Attribution license (http://creativecommons.org/licenses/by/3.0/). 